\title{
Transported into a Story World: The Role of the Protagonist
}

\author{
Anneke de Graaf and Lettica Hustinx
}

\section{Introduction}

Narratives can create an experience that is both intense and impactful. Readers can become deeply engaged with a narrative and its characters, as they focus their complete attention on the events that are described and experience emotions in response to these events. ${ }^{1}$ Readers then lose awareness of the real world and become "lost" in the world created by the narrative. ${ }^{2}$ For many readers, this is a familiar experience. In fact, it is probably one of the main reasons why people read stories. ${ }^{3}$ People enjoy forgetting their daily lives for a while by becoming absorbed in an alternative world. ${ }^{4}$ Given the intense nature of this experience, it is not surprising that such engagement with a narrative can have far-reaching impact. Green and Brock's research has shown that transportation, or the feeling that one is being carried into a narrative world, can make readers' beliefs become more consistent with the beliefs implicitly implied by the story. ${ }^{5}$ Also, engagement with specific characters has been shown to lead readers to align their own attitudes with those of that character. ${ }^{6}$ It is thus clear that the intense narrative experience can impact readers' views of the world.

However, previous research has generally not addressed why certain narratives are more successful in drawing readers into the story, than others. Antecedents of transportation, i.e. the determinants that cause transportation into a narrative world, have scarcely been researched. ${ }^{7}$ In other words, it is still largely unclear which narrative features contribute to engagement with the story and ultimately to the occurrence of persuasive effects. This is why Green

\footnotetext{
$1 \quad$ Busselle and Bilandzic (2008); De Graaf, Hoeken, Sanders and Beentjes (2009); Green (2006).

$2 \quad$ Gerrig (1993); Nell (1988).

$3 \quad$ Slater (2002); Slater and Rouner (2002).

4 Green, Brock and Kaufman (2004).

5 Green and Brock (2000).

6 De Graaf, Hoeken, Sanders and Beentjes (2012).

7 Green (2004).
}

(C) ANNEKE DE GRAAF AND LETTICA HUSTINX, 2015 | DOI 10.1163/9789004270848_008

This is an open access chapter distributed under the terms of the Creative Commons AttributionNoncommercial 3.0 Unported (CC-BY-NC 3.o) License. 
(2008) sees uncovering "the active ingredients of effective narratives" as one of the most important challenges in this research area. ${ }^{8}$ This study takes up that challenge by investigating the influence of a central element of narratives: features of the protagonist. Based on Zillmann's Affective Disposition Theory, the different portrayals of the protagonists' behaviour and personality (as sympathetic, neutral, or unsympathetic) in eliciting transportation is tested. ${ }^{9}$ In the following theoretical framework, the Transportation-Imagery Model of Green and Brock is discussed first. ${ }^{10}$ Then, the Affective Disposition Theory is presented. Finally, the hypotheses of this study are formulated.

\section{Transportation-Imagery Model}

The term transportation is used by Gerrig (1993) as a metaphor for the experience that readers of a story can have during reading. He describes readers as travellers who feel that they have journeyed some distance from their world of origin and into another world. ${ }^{11}$ Following this description, Green and Brock conceptualize transportation as a convergent process, in which all mental systems become focused on events occurring in the narrative. These mental systems are specified as readers' attention, emotion, and imagery. Thus, when readers are transported, their attention is concentrated on the story, they have emotions in response to the story, and they form mental images of the things that are described in the story. In other words, a transported reader imagines the narrative events in "the mind's eye" and experiences the story from the inside, as if the narrative world has been entered. ${ }^{12}$

The Transportation-Imagery Model provides a testable theory of the antecedents and consequences of transportation. The model consists of five postulates that make up a unified account of the complete transportation process. The first two postulates concern the consequences of transportation, which are the persuasive effects of narratives. "Narrative persuasion" refers to a change in readers' beliefs and attitudes after reading a narrative. ${ }^{13}$ The first postulate concerns the prerequisites for such persuasive effects to occur, such as the fact that certain beliefs need to be implied by the narrative before it can

\footnotetext{
$8 \quad$ Green $(2008) 48$.

$9 \quad$ Zillmann (1994, 2006).

$10 \quad$ Green and Brock (2002).

$11 \quad$ Gerrig (1993) 11.

12 Green and Brock (2000, 2002).

13 Green and Brock $(2000,2002)$.
} 
have persuasive effects. The second postulate concerns the mechanism of narrative persuasion, claiming that belief-change occurs to the extent that readers are transported into the narrative world. As transportation consists of attention, emotion and imagery, this postulate concerns these three aspects. Importantly, the type of emotion that is part of transportation is not specified in the model. All types of emotions, from sadness to happiness can contribute to transportation. ${ }^{14}$ In sum, the Transportation-Imagery Model posits that as readers have more attention for, emotional response to, and visual imagery of the story, their beliefs and attitudes will become more consistent with the story.

The persuasive consequences of transportation have been investigated extensively. In their first three experiments, Green and Brock (2000) presented their participants with a story about a young girl who is murdered in a mall by a psychiatric patient on leave. Because an attempted manipulation of transportation was not successful in these experiments, ${ }^{15}$ participants were divided into a group that achieved a higher score on the transportation scale and a group that achieved a lower score on this scale. Results showed that high transportation participants held beliefs more consistent with the story than low transportation participants. For instance, the more transported readers considered malls to be more dangerous and thought that psychiatric patients should have fewer rights to go on leave than the less transported readers. However, as transportation was not successfully manipulated, it is not certain whether transportation actually caused these differences. Therefore, a fourth experiment was carried out, which did succeed in manipulating transportation. This experiment used a story about a young boy who was stranded on an island of ice with his dog. Participants who had been instructed to circle words that they judged too difficult for fourth-grade readers were less transported into the story than participants who had been instructed to read the story normally. Moreover, these participants held beliefs that were less consistent with the story (about the value of friendship and loyalty) than the participants who did not have to carry out an extra task during reading. Mediation analysis

14 Green (2006).

15 One group of participants was instructed to circle all words that they judged too difficult for fourth-grade readers, whereas another group was instructed to read the story like they normally would. It was expected that the first group would show lower levels of transportation into the narrative world because they had to focus on the form of the words and grammar instead of the events in the story. However, results showed that there were no differences between the groups and thus the manipulation of transportation was unsuccessful. 
showed that transportation was indeed responsible for these effects, indicating a causal effect of transportation on persuasion.

Similarly, another series of experiments investigated the effects of engagement with characters. ${ }^{16}$ This type of engagement, also called identification, is an experience that is closely linked to transportation. ${ }^{17}$ Identification refers to adopting the perspective of a character and having emotional responses that are consistent with those of the character. ${ }^{18}$ So, readers of a story who identify with a character also experience the story from within and feel emotions in reaction to the narrative events. De Graaf et al. showed that readers of a story told from the perspective of a specific character, identified more with this character and held attitudes more consistent with this character. Again, mediation analysis revealed that identification was causally responsible for the persuasive effects of the story. ${ }^{19}$ In sum, several studies show that the experience of becoming absorbed in a story and being transported into the story-world leads to narrative persuasion, confirming the first part of the Transportation-Imagery Model about the consequences of transportation.

The second part of the Transportation-Imagery Model, comprising the third, fourth, and fifth postulate, concerns the antecedents of transportation. These postulates state that propensity for transportation by exposure to a given narrative account is affected by attributes of the recipient, attributes of the text, and attributes of the context. So, characteristics of the reader, of the narrative and of the reading situation influence whether a reader becomes transported into a narrative. For instance, regarding attributes of the recipient, readers with an aptitude for forming mental images, i.e. people with a strong imagination, will tend to experience more transportation. ${ }^{20}$ With regard to the attributes of the context, the situation may limit readers' imaginative investment in a narrative. For instance, when there are other people talking loudly in the vicinity of the reader, the reader may be distracted from the story. However, regarding attributes of the text, the theory is not very clear. According to Green and Brock, one of the most important attributes of the text that affects transportation is artistic craftsmanship. If a story is of high quality, it will be more transporting. However, it is unclear what makes a story of high quality. Therefore, this hypothesis is hard to test and the theory does not give concrete indications of story characteristics that will lead to transportation. To

\footnotetext{
16 De Graaf et al. (2012).

17 See Slater and Rouner (2002) 177.

18 Cohen (2001, 2006).

19 De Graaf et al. (2012).

20 Green and Brock (2002).
} 
expand the Transportation-Imagery Model and to gain insight into what makes stories effective at transporting readers into a narrative world, this study focuses on the role of attributes of the text in transportation.

Some preliminary studies have investigated characteristics of narratives that can promote transportation. De Graaf and Hustinx have looked at the influence of story structure. They used a story about a man who falls ill and tries different cures to get better. In one version of the story, the final outcome of him getting better was already disclosed at the beginning of the story, after which the treatments are described. In the other version of the story, readers only got to know this final outcome at the end after reading about the different treatments. The latter version in which it is unclear to readers what the outcome will be, was expected to elicit more emotion and transportation because readers are in suspense about what will happen, compared to the other version in which readers already know from the beginning that the character will be cured. Results indeed showed that readers of the suspenseful version reported higher transportation on both the emotion and the attention subscales. This shows that readers who did not yet know the outcome were more absorbed in the story. Thus, story structure is a characteristic that can influence transportation. ${ }^{21}$

In a different study, it was assessed whether the perspective of the story affects transportation. ${ }^{22} \mathrm{~A}$ version of a story with an omniscient narrator was compared to a version of the same story told by a first-person narrator. The omniscient narrator referred to the protagonist as "he" and presented both his thoughts and the thoughts of other characters. The first-person narrator referred to the protagonist (himself) as "I" and presented only his own thoughts. The latter version was expected to bring readers closer to the protagonist and thus elicit more emotions. Results indeed showed that the story told by the first-person narrator was more transporting; participants who had read this version reported more emotion and more attention for the story than participants who had read the story told by the omniscient narrator. ${ }^{23}$ These results were corroborated by the previously mentioned study of De Graaf et al. (2012), who showed that the perspective of a story led to more engagement with characters, which is closely linked to transportation. Thus, story perspective is a story characteristic that can influence transportation.

These studies provide specific story attributes that promote transportation and thus provide insight into antecedents of transportation. They also provide

\footnotetext{
21 De Graaf and Hustinx (2011).

22 Hustinx and Smits (2006).

23 Hustinx and Smits (2006).
} 
a starting point for a more general narrative element that could play a role in transportation. These studies showed that stories that bring readers closer to the protagonist of a story make readers become more transported into the story world. This suggests that the protagonist may be important for transportation. This has been shown for the perspective from which the protagonist is presented, ${ }^{24}$ but other features of the protagonist may also increase transportation. If it is shown that different features of a character that bring readers close to the character consistently lead to transportation, we will have found a clear and concrete antecedent of transportation to add to the TransportationImagery Model. Therefore, we turn to the Affective Disposition Theory, which provides another feature that promotes closeness to characters. ${ }^{25}$

\section{Affective Disposition Theory}

Affective Disposition Theory was developed to explain the emotions recipients feel in response to stories. The theory posits that the emotions that are evoked by a story are dependent on the dispositions that readers ${ }^{26}$ have towards the characters. A disposition refers to the extent that a reader cares for the character. If a reader likes a character, the reader has a positive disposition toward the character; if a reader is indifferent toward a character, the reader has a neutral disposition toward the character and if a reader does not like a character, he or she has a negative disposition. Affective Disposition Theory posits that these dispositions predict the extent and the type of emotion a reader will feel for a character. $^{27}$

Only if a reader has either a positive or a negative disposition toward a character, does the reader care what will happen to the character and feels emotions as a result of that character's experiences. If a reader has a neutral disposition, he/she does not care what happens to the character and feels no emotion in response to the events in the story. Importantly, the type of emotion differs between a positive and a negative disposition, whereas the extent of emotion differs between a neutral disposition on the one hand and a positive

\footnotetext{
24 Hustinx and Smits (2006); de Graaf et al. (2012).

25 Zillmann (1994, 2006).

26 In his publications, Zillmann $(1994,2006)$ talks about "viewers" because he focuses on stories in the theater and on television. However, since the theory is about characters and the events they experience, it should also be applied to written stories. As written stories are the focus of this study, we will use the term readers.

Raney (2004); Zillmann (1994, 2006).
} 
and negative disposition on the other hand. Regarding the type of emotion, Affective Disposition Theory predicts that if a reader has a positive disposition toward a character, the reader wants the character to succeed and hopes positive events will happen to the character. Oatley $(1994,1999)$ argues that this evokes empathy. ${ }^{28}$ The reader is happy when good things happen to the character and sad when bad things happen. The reader's emotions are then consistent with the emotions of the character. ${ }^{29}$ Conversely, if a reader has a negative disposition toward a character, the reader wants the character to fail and hopes negative events will happen to the character. This evokes counter-empathy. The reader is happy when bad things happen to a character and sad when good things happen. In this case, the reader's emotions are in opposition to the emotions of the character ${ }^{30}$ However, the extent of emotions (although of opposite valence) can be the same for readers who have a positive and a negative disposition. Affective Disposition Theory predicts that readers who have a neutral disposition experience less emotions than readers with either a positive or negative disposition.

According to Affective Disposition Theory the dispositions that readers have toward characters are dependent on the characters' moral conduct. If a character performs morally good actions, the reader will form a positive disposition towards the character; if a character only performs actions that are neither morally good nor bad, the reader will form a neutral disposition toward the character and if a character performs morally bad actions, the reader will form a negative disposition. ${ }^{31}$ In other words, if a character behaves sympathetically, the character will be liked, if a character behaves neutrally, the character will be met with indifference, and if a character behaves unsympathetically, the character will be disliked. In our view, other elements than behaviour can contribute to the sympathy shown toward a character, such as thoughts, utterances, and judgments of other people's behaviour.

In summary, readers form a disposition or attachment to characters in a story from negative through neutral to positive on the basis of the characters' conduct and personality. So, sympathetic behaviour and personality should lead to a positive disposition, which evokes empathy with the character, whereas unsympathetic behaviour and personality should lead to a negative disposition, which evokes counter-empathy. If readers have a neutral disposition toward a character, no emotions should be evoked. To see whether these

\footnotetext{
$28 \quad$ Oatley $(1994,1999)$.

29 Cohen (2001); Tan (1994).

30 Zillmann (1994, 2006).

$31 \quad$ Raney (2004); Zillmann (1994, 2006).
} 
predictions are correct, an experiment was conducted that compared a story with a sympathetic, a neutral, and an unsympathetic protagonist.

\section{Hypotheses}

The aim of this study is to find a narrative element that affects transportation, so that we can add this element as a concrete antecedent of transportation to the Transportation-Imagery Model. We focus on an element that influences the emotion evoked by a story, which is one of the three aspects of transportation. Affective Disposition Theory provides a character feature that promotes emotions, which is the extent to which a character is described as a sympathetic person. If a reader cares for a character because he acts and thinks sympathetically, the reader will feel empathy; if a reader is indifferent toward a character, the reader will feel no empathy, and if a reader dislikes a character because he is described as an unsympathetic person, the reader will feel counter-empathy. Based on this reasoning, the first three hypotheses of this study are:

H1 Readers of a story with a sympathetic protagonist have a more positive disposition toward the protagonist than readers of the story with a neutral protagonist, who in turn have a more positive disposition than readers of the story with an unsympathetic protagonist.

$\mathrm{H} 2$ Readers of a story with a sympathetic protagonist feel more empathy for the protagonist than readers of the story with a neutral protagonist, who in turn feel more empathy than readers of the story with an unsympathetic protagonist.

$\mathrm{H}_{3}$ The effect of the protagonist's portrayal on empathy is mediated by the disposition toward the character.

Empathy is expected to be less for the unsympathetic protagonist because this character likely evokes counter-empathy. However, such counter-empathy is also a type of emotion. Therefore, Affective Disposition Theory predicts that readers of the sympathetic version, as well as readers of the unsympathetic version, feel more emotion than readers of the neutral version. This is important because the Transportation-Imagery Model posits that the extent of emotion evoked by the story contributes to transportation, without specifying the type of emotion. So, when Affective Disposition Theory and the Transportation-Imagery Model are combined, it can be predicted that the versions with the sympathetic protagonist and with the unsympathetic protagonist lead to 
more emotion and transportation than the version with the neutral protagonist.

$\mathrm{H}_{4}$ Readers of a story with a sympathetic protagonist or an unsympathetic protagonist feel more emotion in response to the story than readers of the story with a neutral protagonist.

$\mathrm{H}_{5}$ Readers of a story with a sympathetic protagonist or an unsympathetic protagonist experience more transportation into the narrative world than readers of the story with the neutral protagonist.

H6 The effect of the protagonist's portrayal on transportation is mediated by empathy with that character.

Finally, based on the Transportation-Imagery Model, the consequences of transportation are also tested. ${ }^{32}$ In the study by Hustinx and Smits, manipulation of perspective had no impact on the participants' beliefs. ${ }^{33}$ However, since the protagonist has been portrayed more sympathetically than in that original story, persuasive effects may occur in the present study. Therefore, the final hypotheses are:

$\mathrm{H}_{7}$ Readers of a story with a sympathetic protagonist have beliefs more consistent with the story than readers of the stories with neutral or unsympathetic protagonists.

H8 The effect of the protagonist's portrayal on beliefs will be mediated by transportation into the story world.

\section{Method}

\section{Materials}

To test the hypotheses, a literary story by the well-known Dutch author Tim Krabbé, titled "The Matador" (1982), was used as base material. This story was chosen because it has suspenseful content and allows readers to become transported, but it is still possible to read the story in an experimental session. Also, it has a clear protagonist that can be manipulated into a sympathetic, a neutral, and an unsympathetic person, so that it can be tested whether this actu-

32 Green and Brock (2000, 2002).

33 Hustinx and Smits (2006) 
ally influences transportation. ${ }^{34}$ All versions of the story had a length of approximately 4300 words.

The story is about a man, named Schwab, who makes a sentimental journey to the town Lequito in the Basque country in Spain, which he first visited 15 years ago with his former lover Ellie. At the beginning of the story, he walks around and takes pictures of places that have sentimental value to him. Several days later, when he is leaving the Basque country via a car through the mountains, he is overtaken by a van and forced to stop. Masked men overpower Schwab and throw him into the van. He remembers that several days earlier the governor was kidnapped by the ETA. He is questioned roughly on a desolate farm about why he took photographs in Lequito. He recognizes the leader of the group as the matador whom he and Ellie had befriended during his first visit 15 years ago. But the man does not remember him and Schwab is blindfolded and executed.

To manipulate the readers' disposition toward the protagonist, three versions of the story were constructed. In the main this was done by adding information that was either positive, neutral, or negative about the character's actions and thoughts. At some points in the text in which character descriptions were provided, information from the base story was changed in the different versions. In the "sympathetic" version, Schwab is portrayed as a good man who behaves in a kind manner. For instance, when he is walking around in Lequito, he sees a kitten approaching him. His response in this version is: "He bent over to pet the kitten. He had always been an animal lover." In the "neutral" version, the things he does are neither positive nor negative. For example his response to the kitten is: "He sat down on a bench and looked at the kitten." In the "unsympathetic" version, the protagonist is portrayed as an unpleasant person who thinks badly about others and acts accordingly. In this version, he responds to the kitten negatively: "He kicked the ugly animal to the side. He had always hated cats." Similarly, the descriptions of the protagonist's thoughts were manipulated. For instance, asking a sour-looking passer-by to take a picture of him, the sympathetic protagonist thinks: "She looked much friendlier up-close. She would definitely agree to take a picture." In the neutral version, the protagonist thinks: "He could always try. Nothing ventured, nothing gained," whereas the unsympathetic protagonist thinks: "He probably should not even bother to try asking the woman with the grumpy face." The first part consisted of approximately 1900 words in all three versions.

In the part of the story where the protagonist is kidnapped by the ETA (approximately 2400 words), the sympathetic version portrays Schwab as brave, 
which is likely to elicit a positive response from the reader for the protagonist. For instance: "Schwab realized he had to stay calm. If he were to explain everything calmly, they would see their mistake." In the neutral version, the protagonist asks a lot of questions, and is unsure about how to behave. For instance he thinks: "What should he do now? Should he protest? Or say nothing?" In the unsympathetic version, the protagonist acts negatively, displaying cowardice: "Schwab realized he had always been a coward." In sum, the characters were manipulated so that they appeared either as a good person, a person that is neither good nor bad, or a bad person.

However, the basic plot remained the same over the three versions. The protagonist visits the Basque country as a tourist, and is kidnapped by the ETA and executed, thus implying that the Basque country is a dangerous place.

\section{Participants and Procedure}

A total of 83 high school students who were in their fifth year of pre-academic studies ( 5 Vwo) participated in this experiment. ${ }^{35}$ There were 33 men $(39.8 \%)$ and 50 women $(60.2 \%)$ and their ages ranged from 16 to 18 with a mean of 16.87 years. These participants were randomly assigned to read one of the three conditions in a between-subjects design; 28 participants read the version with the sympathetic protagonist, 28 participants read the neutral version, and 27 participants read the unsympathetic version. All participants read the story in the familiar context of their own high school. The experiment leader gave all the participants the same instructions about concentrating on the story without talking. Participants were not aware of any different versions. The experiment lasted approximately 30 minutes.

\section{Questionnaire}

After reading the story, participants filled in a questionnaire that measured the relevant variables. The questionnaire consisted of items about readers' disposition toward the protagonist, empathy with the protagonist, transportation into the narrative world, beliefs implied by the story and the personal characteristics of gender and age.

Participants' disposition toward the protagonist was measured with two items concerning the extent to which they liked the character. These items formed a reliable scale (Cronbach's $\alpha=.87$ ). An example item is: "I think Schwab is a sympathetic person." Participants' empathy with the protagonist was mea- 
sured with three items. These items formed a reliable scale (Cronbach's $\alpha=.71)$. An example item is: "During reading, I empathized with Schwab."

Transportation into a narrative world was measured with items based on Green and Brock's (2000) transportation scale. The components emotion, attention and imagery were measured separately. Emotion was measured with four items concerning the feelings participants had in response to the story. These items formed a reliable scale (Cronbach's $\alpha=.84$ ). An example item is: "The story affected me emotionally." Attention was measured with five items about the extent to which they were not distracted. These items formed a reliable scale (Cronbach's $\alpha={ }_{\text {.74}}$ ). An example item is: "While I was reading the narrative, activity going on around me was on my mind" (reverse scored). Imagery was measured with six items about the mental images participants formed. These items formed a reliable scale (Cronbach's $\alpha=.70$ ). An example item is: "During reading, I had a vivid image of Schwab." In addition to the separate components of transportation, we computed the complete transportation scale that consists of all items of the three components. This complete scale also had a good reliability ( 15 items, Cronbach's $\alpha=.82$ ).

Finally, beliefs were measured with five items about the danger of the Basque country and the ETA. These were consistent with the measures used in the previous study. These items formed a reliable scale (Cronbach's $\alpha=.79$ ). An example item is: "The Basque country is not a safe destination for tourists." All items were answered on a seven point Likert scale ranging from "completely disagree" to "completely agree."

\section{Results}

Mean scores and standard deviations of our dependent measures by condition are reported in Table 6.1.

\section{Affective Disposition and Empathy}

Regarding hypothesis 1 and 2 about the effects of the protagonist's portrayal on the affective disposition that readers have towards the protagonist and on empathy with the protagonist, univariate analyses were carried out that compared the three versions of the story. The analyses showed that the type of portrayal had a significant effect on readers' dispositions $\left(F(2,80)=50.34, p<.001, \eta^{2}=\right.$ $.56)$. Participants who had read the version with the sympathetic protagonist liked the protagonist more than participants who had read the neutral version, who in turn liked him more than in the unsympathetic version (all $p$ 's $<.001$ ). Also, the protagonist's portrayal had a significant effect on empathy with the 
TABLE 6.1 Means and standard deviations (between brackets) of affective disposition, empathy, transportation and beliefs by condition $(1=$ very low, $7=$ very high $)$.

\begin{tabular}{llll}
\hline & $\begin{array}{l}\text { Sympathetic } \\
\text { protagonist }\end{array}$ & $\begin{array}{l}\text { Neutral } \\
\text { protagonist }\end{array}$ & $\begin{array}{l}\text { Unsympathetic } \\
\text { protagonist }\end{array}$ \\
\hline Affective disposition & $5.39(0.81)^{\mathrm{a}}$ & $4.25(0.98)^{\mathrm{b}}$ & $2.89(0.98)^{\mathrm{c}}$ \\
Empathy & $5.13(0.80)^{\mathrm{a}}$ & $4.58(1.11)^{\mathrm{b}}$ & $4.09(1.18)^{\mathrm{c}}$ \\
Emotion & $4.74(1.22)^{\mathrm{a}}$ & $3.96(1.19)^{\mathrm{b}}$ & $4.10(1.37)^{\mathrm{b}}$ \\
Attention & $5.32(0.72)^{\mathrm{a}}$ & $5.04(0.91)^{\mathrm{a}}$ & $4.43(1.30)^{\mathrm{b}}$ \\
Imagery & $4.89(0.83)$ & $4.60(0.91)$ & $4.75(1.05)$ \\
Transportation* & $4.99(0.63)^{\mathrm{a}}$ & $4.58(0.71)^{\mathrm{b}}$ & $4.47(1.06)^{\mathrm{b}}$ \\
Beliefs & $5.21(1.08)$ & $5.19(0.95)$ & $5.30(1.17)$ \\
\hline
\end{tabular}

Note: Means with different superscripts differ significantly. ${ }^{*}$ The scale for Transportation is a combination of the scales for emotion, attention and imagery.

character $\left(F(2,80)=6.89, p<.01, \eta^{2}=.15\right)$. Participants who had read the version with the sympathetic protagonist empathized more with the protagonist than readers of the neutral version $(\mathrm{p}<.05$, one-sided), who in turn empathized more than readers of the unsympathetic version $(p<.05$, one-sided).

Hypothesis 3 about the mediation of readers' disposition was tested for the difference between the positive and the negative version. Descriptive information about the indirect effect is given in Figure 6.1. A test of the indirect effect was carried out using Preacher and Hayes' (2008) bootstrapping method. Results showed that the mediation effect was significant $(B=1.28, S E=.38,95 \% \mathrm{CI}$ $=.5539$ to 2.0783 ).

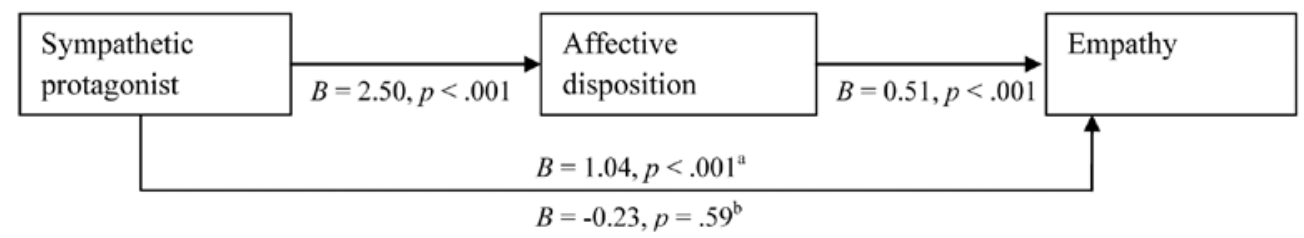

\footnotetext{
${ }^{a}$ regression of protagonist on empathy when affective disposition is not entered.

${ }^{\mathrm{b}}$ regression of protagonist on empathy when affective disposition is entered.
}

FIGURE 6.1 The indirect effect of the protagonist's portrayal through readers' dispositions on empathy. 


\section{Emotion and Transportation}

Regarding hypothesis 4 and 5 about the effects of the protagonist's portrayal on emotion and transportation, univariate analyses were carried out for the separate components of transportation, which are emotion, attention, and imagery, and for the complete transportation scale. The analyses showed that the protagonist's portrayal had a marginally significant effect on readers' emotion $\left(F(2,80)=3.03, p=.054, \eta^{2}=.07\right)$. There was a significant difference between the sympathetic and the neutral version $(p<.05)$, such that readers of the sympathetic version felt more emotion. Also, there was a significant difference between the sympathetic and the negative version $(p<.05$, one-sided). Again, readers of the sympathetic version felt more emotion.

The protagonist's portrayal also had a significant effect on attentional focus $\left(F(2,80)=5 \cdot 70, p<.01, \eta^{2}=.12\right)$. For attention, readers of the unsympathetic version differed significantly from both the neutral and the sympathetic version (both $p$ 's <.05). Readers had less attention when they read the version in which the protagonist performed negative actions. There were no differences between the versions for imagery $\left(F(2,80)=0.66, p=.5^{2}\right)$. Finally, the protagonist's portrayal had a significant effect on transportation as a whole $(F(2,80)=$ 3.14, $\left.p<.01, \eta^{2}=.07\right)$. Readers of the positive version were more transported into the story than readers of the negative version $(p<.05)$ and readers of the neutral version $(p<.05$, one-sided).

Hypothesis 6 about the mediation of empathy was tested for the difference between the positive and the negative version. Descriptive information about the indirect effect is given in Figure 6.2. Results of the bootstrapping test showed that the mediation effect was significant $(B=0.65, S E=.19,95 \% \mathrm{CI}=$ .3062 to 1.0532$)$.

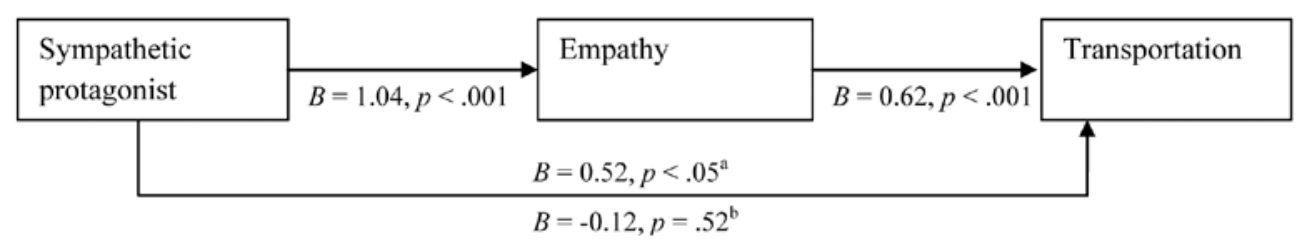

\footnotetext{
${ }^{a}$ regression of protagonist on transportation when empathy is not entered.

${ }^{\mathrm{b}}$ regression of protagonist on transportation when empathy is entered.
}

FIGURE 6.2 The indirect effect of the protagonist's portrayal through empathy on transportation. 


\section{Beliefs}

Regarding hypothesis 7 about the effect of the protagonist's portrayal on beliefs, univariate analysis showed that there was no difference between the versions on beliefs $(F(2,80)=0.96, p=.91)$. Participants held beliefs equally consistent with the story after reading all versions. Therefore, hypothesis 8 about the mediation of transportation could not be tested.

\section{Conclusion and Discussion}

This study set out to find an antecedent of transportation to add to the Transportation-Imagery Model. ${ }^{36}$ Based on Affective Disposition Theory, the portrayal of the protagonist's behaviour and thoughts as sympathetic, neutral or unsympathetic, were tested as a potential antecedent. ${ }^{37}$ Hypotheses 1 and 2 about the effect of the protagonist's portrayal on readers' affective dispositions and empathy were confirmed. Readers of the version of the story with the sympathetic protagonist had a more positive disposition toward the protagonist and empathized more strongly with him than readers of the story with the neutral protagonist who in turn had more positive dispositions and empathized more strongly than readers of the story with the unsympathetic protagonist. In line with hypothesis 3 , we were able to show that the impact on the level of empathy was mediated through affective disposition. These results corroborate Affective Disposition Theory.

Hypothesis 4 about the effect of the protagonist's portrayal on emotion was partly confirmed. Readers of the version of the story with the sympathetic protagonist felt more emotion in response to the story than readers of the version with the neutral protagonist. However, the version with the unsympathetic protagonist did not evoke more emotion than the version with the neutral protagonist. A similar pattern was obtained with regard to the transportation scale as a whole $\left(\mathrm{H}_{5}\right)$. Readers of the story with the sympathetic protagonist experienced more transportation into the narrative world than readers of the stories with a neutral or unsympathetic protagonist. A possible explanation for these results lies with the ending of the story.

To keep the content of the story consistent, the ending of the story was the same in all three versions: the protagonist was killed. The unsympathetic version described the protagonist as engaging in actions and thoughts that were morally reprehensible, but not so negative as to warrant such an outcome.

$36 \quad$ Green and Brock (2002).

37 Zillmann $(1994,2006)$. 
Therefore, it is unlikely that readers were happy with the outcome, which in turn would have limited transportation evoked by the story. Since this model works on the supposition that no reader would wish a violent death upon someone whose previous actions, whilst repugnant, do not place him beyond redemption.

Future research should incorporate the story outcome as an independent variable to gain more insight into the effects of this important story element. A proportionally more appropriate ending might have met with more emotion and transportation in the readers of the unsympathetic version as well.

Another potential explanation for these results is that readers may have felt more similar to the sympathetic protagonist. As people generally hold a positive self-image and thus think of themselves as sympathetic, they may have perceived themselves as having more in common with the protagonist in the sympathetic version. Since perceived similarity is positively linked to empathy, ${ }^{38}$ the more sympathetic protagonist may have evoked more emotion and transportation through such a perception. However, since Schwab was a middle-aged man reminiscing about his past, it is also likely that the high school students that participated in this research did not find themselves very similar to the protagonist in any version. To establish whether similarity plays a role in the effects of a sympathetic protagonist, future research should include a measure of perceived similarity between reader and protagonist. Preferably, this measure would be included in a study that also varies the story outcome as outlined above, so that it can be established whether an unsympathetic protagonist leads to less emotion and transportation through a perception of dissimilarity or whether it can also lead to more emotion when a proportionally appropriate ending is included.

The different levels of transportation between the groups, who read different versions of the story, were due to the emotional and attentional component of the transportation scale. The other component of transportation, mental imagery, did not differ between versions. This is consistent with the results of previous studies that also did not find an effect of text characteristics on imagery. ${ }^{39}$ Perhaps this component of transportation is not influenced by attributes of the text as much as emotion and attention are. This component may rather be dependent on attributes of the recipient, like the strength of their imagination. Nevertheless, there were differences in the participants' transportation, showing that readers of the sympathetic protagonist version were more absorbed in the narrative world and less aware of their surround-

38 Cohen (2001, 2006), De Graaf and Hustinx (2012).

39 Hustinx and Smits (2006); De Graaf and Hustinx (2011). 
ings. Moreover, hypothesis 6 concerning the mediation of readers' empathy in the effect of the protagonist's portrayal on transportation was confirmed. The portrayal influenced empathy with the protagonist, which in turn led to transportation.

With these results, we have indeed found a previously undisclosed antecedent of transportation. The protagonist's portrayal as sympathetic, neutral, or unsympathetic influenced the extent to which readers were transported. If the protagonist was found more sympathetic, more transportation occurred. In combination with the results from previous studies, this study provides a strong indication that narrative elements that bring the reader close to a character, either by presenting the story from their perspective or by making a character more sympathetic, actually lead to transportation. Because this has now been shown for multiple character features, showing that it is a replicable and stable effect, the protagonist can be confidently added to the TransportationImagery Model as an antecedent of transportation. ${ }^{40}$

Finally, hypothesis 7 about the effect of the protagonist's portrayal on beliefs was not confirmed. Readers of all three versions held beliefs equally consistent with the story. A possible explanation is that perhaps the effect sizes for transportation were too small for the effect to influence beliefs. It could also be that the topic of the story limited the story's persuasive power in the present sample of participants. Of course, the majority of Dutch high school students do not have an affinity with the Basque country and the ETA. The study that previously used this story also did not find any persuasive effects. ${ }^{41}$ This indicates that differences in transportation may not always lead to persuasion. Therefore, it is important for future research to investigate when transportation leads to persuasion and when it does not. In other words, researchers should uncover moderating factors of narrative persuasion. Involvement with the topic of a story could be such a factor.

A limitation of this study that is related to this point, is that only one story was used to test the hypotheses. Such a single message design has been used in all research about narrative persuasion so far, but this design makes it hard to draw conclusions about stories other than the one that has been used. Therefore, replication is needed with different stories. If potential moderators of narrative persuasion are manipulated systematically, factors can be identified that limit or facilitate persuasion by narratives.

Another limitation of this study concerns the sample of participants. Although high school students have sufficient reading ability to understand

\footnotetext{
$40 \quad$ Green and Brock (2002).

41 Hustinx and Smits (2006).
} 
stories, it is also likely that they have less experience and prior knowledge than adults. Therefore, adults' reactions to the story could differ. However, even though the story was about a forty-something male dreaming about an old romance, transportation of these high school students was still moderate (above the neutral midpoint). Apparently, transportation is a pervasive process during reading. This makes it all the more important to identify factors that influence the extent to which a reader is transported. Our results show that the protagonist plays a key role in transportation. Features of the protagonist that made him a sympathetic person, increased the level of readers' transportation. Since antecedents of transportation have scarcely been researched, this is an important contribution to the literature. Future research should continue to identify narrative elements that influence transportation.

\section{References}

Busselle, R. and H. Bilandzic, "Fictionality and perceived realism in experiencing stories: A model of narrative comprehension and engagement," in Communication Theory 18 (2008), pp. 255-80.

Cohen, J., "Defining identification: A theoretical look at the identification of audiences with media characters," in Mass Communication and Society 4(3) (2001), pp. $245^{-64}$.

, "Audience identification with media characters," in Psychology of Entertainment, eds. J. Bryant and P. Vorderer (Lawrence Erlbaum, 2006), pp. 183-97.

Gerrig, R.J., Experiencing narrative worlds (Yale University Press, 1993).

De Graaf, A., H. Hoeken, J. Sanders and H. Beentjes, "The role of dimensions of narrative engagement in narrative persuasion," in Communications: The European Journal of Communication Research 34(4) (2009), pp. 385-405.

—_, "Identification as a mechanism of narrative persuasion," in Communication Research 39(6) (2012), pp. 802-23.

De Graaf, A. and L. Hustinx, "The effect of story tructure on emotion, transportation, and persuasion," in Information Design Journal 19(2) (2011), pp. 140-52.

—_, "Waargenomen gelijkenis, identificatie en narratieve overtuiging" [Perceived similarity, identification, and narrative persuasion]. In De stralende lezer: Wetenschappelijkonderzoeknaar de invloed van het lezen, ed. F. Hakemulder(Eburon, 2012), pp. 183-200).

Green, M.C., "Transportation into narrative worlds: The role of prior knowledge and perceived realism," in Discourse Processes 38(2) (2004), pp. 247-66.

—_, "Narratives and cancer communication," in Journal of Communication 56 (2006), pp. $163-83$. 
- , "Research challenges in narrative persuasion," in Information Design Journal 16(1) (2008), pp. 47-52.

Green, M.C. and T.C. Brock, "The role of transportation in the persuasiveness of public narratives," in Journal of Personality and Social Psychology 79(5) (2000), pp. 701-21.

___ " "In the mind's eye: Transportation-imagery model of narrative persuasion," in Narrative impact: Social and cognitive foundations, eds. T.C. Brock, J.J. Strange and M.C. Green (Erlbaum, 2002), pp. 315-41.

Green, M.C., T.C. Brock and G.F. Kaufman, "Understanding media enjoyment: The role of transportation into narrative worlds," in Communication Theory 14(4) (2004), pp. 311-27.

Hoeken, H. and L. Hustinx, "The impact of exemplars on responsibility stereotypes in fund-raising letters," in Communication Research 34(6) (2007), pp. 596-617.

Hustinx, L. and A. Smits, "Meegevoerd in de narratieve wereld: De invloed van het verhaalperspectief op de aandacht, emoties en overtuigingen van de lezer" [Carried into the narrative world: Influence of story perspective on attention, emotion and beliefs of the reader], in Studies in taalbeheersing 2, eds. H. Hoeken, B. Hendriks and P.J. Schellens (van Gorcum, 2006), pp. 132-43.

Krabbé, T., "De Matador," in De Matador en andere verhalen [The Matador and other stories] (Amsterdam: Bert Bakker, 1982).

Nell, V., Lost in a book: The psychology of reading for pleasure (Yale University Press, 1988).

Oatley, K., "A taxonomy of the emotions in literary response and a theory of identification in fictional narrative," in Poetics 23 (1994), pp. 53-74.

__ , "Meeting of minds: Dialogue, sympathy and identification in reading fiction," Poetics 26 (1999), pp. 493-54.

Preacher, K. and A. Hayes, "Asymptotic and resampling strategies for assessing and comparing indirect effects in multiple mediator models," in Behavior Research Methods 40(3) (2008), pp. 879-91.

Raney, A.A., "Expanding disposition theory: Reconsidering character liking, moral evaluations, and enjoyment," in Communication Theory 14(4) (2004), pp. 348-69.

Slater, M.D., "Involvement as goal-directed strategic processing: Extending the Elaboration Likelihood Model," in The Persuasion Handbook: Developments in Theory and Practice, eds. J.P. Dillard and M. Pfau (Sage, 2002), pp. 175-94.

Slater, M.D. and D. Rouner, "Entertainment-education and elaboration likelihood: Understanding the processing of narrative persuasion," in Communication Theory $12(2)$ (2002), pp. 173-91.

Tan, E.S.H., "Film-induced affect as a witness emotion," in Poetics 23 (1994), pp. 7-32.

Zillmann, D., "Mechanisms of emotional involvement with drama," in Poetics 23 (1994), pp. 33-51.

__ , "Empathy: Affective reactivity to other's emotional experiences," in Psychology of Entertainment, eds. J. Bryant and P. Vorderer (Erlbaum, 2006), pp. 151-81. 